\title{
Suicidalitetens könsparadox. Ett neurobiologiskt perspektiv
}

\author{
Av Jan Beskow
}

KVINNORS SUICIDALITET är annorlunda än mäns. Globalt är antalet självmord per 100 ooo dubbelt så vanligt hos män som hos kvinnor. Kvinnor söker oftare för psykiska besvär, men gör trots det fler självmordsförsök och tänker oftare på självmord (WHO, 2015).

Pågående depression och tidigare suicidförsök är de tyngsta riskfaktorerna för självmord. Båda är vanligare hos kvinnor än hos män. Man borde därför förvänta sig en högre självmordsfrekvens bland kvinnor men i själva verket är det tvärtom. Suicid bland män är 2-5 gånger vanligare än hos kvinnor. Denna «suicidalitetens paradox» är ännu så länge otillräckligt förstådd. Nya fynd inom hiärnforskningen är ett nytt bidrag till denna förståelse.

\section{Manlig depression och manlig suicidalitet}

Genom utbildning av allmänläkare om depression och suicidalitet lyckades Wolfgang Rutz med stöd av Svenska kommittén för prevention och behandling av depression sänka självmordstalet på Gotland (Rutz oa 1992 a, Rutz 1992 b). En senare analys visade att det var kvinnornas suicidtal som sänktes, inte männens (Rutz oa, 1995 och 1997). Psykologiska autopsier visade att männen sällan hade kontakt med hälso- och sjukvård men oftare med polis, missbruksvård, socialvård och skattemyndigheter. Männen visade också ett återkommande «pseudopsykopatiskt» beteende (Rutz, 2016), som senare kom att sammanfattas i «Gotlandsskalan for manlig depression» (Rutz, 2016).

Varför är det så? Kliniska observationer stämmer väl med Rutz forskningsfynd. Det lägre självmordstalet hos kvinnor förklaras då ofta med att kvinnor är mer relationstränade och har bättre kontakt med sin kropp. Deras tabuering av kropp och suicidalitet är också mindre. Allt detta gör att de lättare identifierar och talar om sina psykiska besvär och därför kommer till vård snabbare. För män är det svårare att acceptera att de skulle kunna ha en psykisk sjukdom och till och med vara på gränsen till att inte orka leva längre. De undertrycker därför gärna sina symtom, tycker inte de behöver någon hïälp (Fässberg, 2015). De undertrycker också sina suicidala tankar och planer, som senare oväntat kan dyka upp vid en ny påfrestning ofta kombinerat med egenbehandling med alkohol, varefter en del av dem snabbt och effektiv dödar sig själva.

\section{Modern hjärnforskning}

Nya perspektiv på detta område har nu kommit genom modern hï̈rnforskning. Utgångspunkten är studier som visar att olika former av barndomstrauman, finns i bakgrunden till många psykiska störningar. När forskarna sammanfattar ett stort antal studier blir det allt tydligare att bristfällig anknytning och tidiga trauman kan resultera i livslånga hïänförändringar, som i sin 


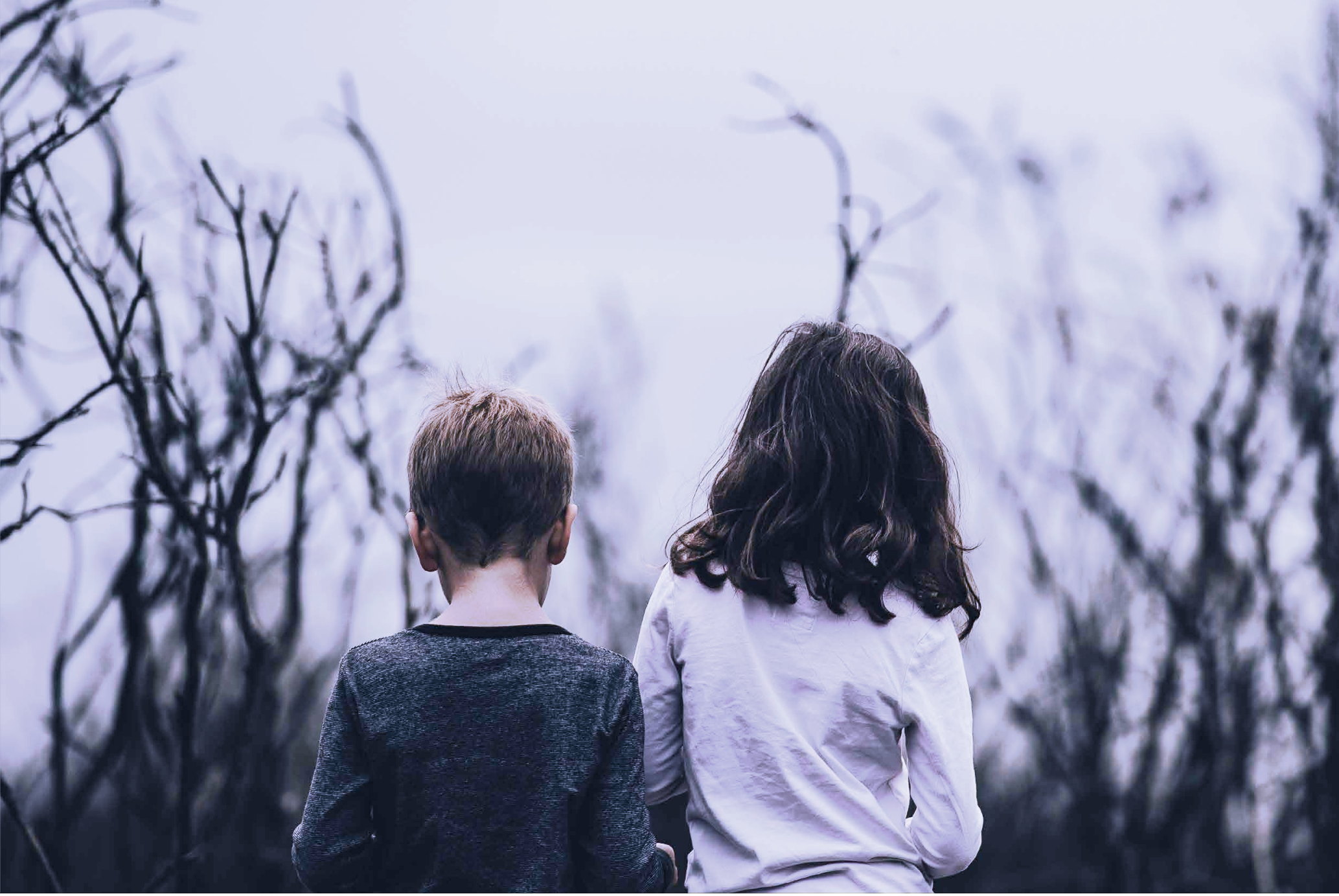

tur ger ökad risk för PTSD, ångest och depression samt att suicidalitet är olika utformad hos män och kvinnor (Teicher, 2016). Dessa fynd motsäger inte utan fördjupar Rutz iakttagelser.

Maltreatment och misshandel. Det handlar här om olika former av utifrån kommande «maltreatment», som är ett vidare begrepp än den svenska översättningen «misshandel». Maltreatment innebär «att ständigt eller upprepat utsättas för händelser som innebär

De neurobiologiska fynden talar för att psykiska trauman under barndomen ger livslånga förändringar i hiärnan.

förlust av förtroende och tillit» medan svenskans «misshandel» ligger nära den juridiska termen «assault». Maltreatment inne-

håller aktiva former såsom fysisk misshandel, sexuellt utnyttjande och mobbning men också passiva former, som stämmer bättre med vårt begrepp «vanvård» eller «negligering», engelskans «neglect». Andra termer utgår från vad som händer i den drabbades kropp såsom «tidig barndomsstress», "Adverse Childhood Experience», ACE och/eller «Early Stress Experience».

\section{Neurobiologi}

Identifiering av psykiska trauman samt tiden när de inträffade görs retrospektivt i 2o-årsåldern bl.a. genom skalan Maltreatment and Abuse Chronology of Exposure (MACE-skalan), (Teicher \& Parigger, 2015). Med denna fångas åtta olika former av misshandel och vanvård av föräldrar och/eller kamrater samt två former av bevittnat familjevåld. Vid vilken ålder händelserna inträffade noteras liksom deras intensitet.

Uppgifterna jämförs sedan med olika former av bildering, främst fMRI. Perioder av hög stressnivå ger inte bara psykologiska skador åtkomliga genom samtal utan också irreversibla hiärnförändringar: Scars that won't heal (Teicher 2012), och The body keeps the score (van der Kolk, 2014). Hos en del personer kan dessa kompenseras genom hiärnans flexibilitet.

Skadorna uppkommer under särskilt känsliga perioder. För pojkarna handlar det om passiva handlingar, negligering i tidig barndom upp till fyra års ålder och för flickorna om att från nio års ålder och under tonårstiden utsättas för aktiva handlingar såsom sexuellt utnyttjande. Att bedömningarna är retrospektiva medför givetvis vissa tolkningssvårigheter. Upplevelsen av ett trauma i tonåren kan t.ex. täcka över sådana upplevelser under de tidigaste barnaåren. Även flickor har erfarenheter av negligering, vilket hos dem, men inte hos männen, är korrelerat till suicidförsök senare under livet (Ehnvall oa, 2008). 


\section{Depression, ångest och PTSD}

De neurobiologiska fynden talar för att psykiska trauman under barndomen ger livslånga förändringar i hiärnan (Teicher \& Samson, 2013). Dessa orsakar psykiska sjukdomar snarare än är konsekvenser av dem. De gör dessutom att sjukdomarna debuterar tidigare, får allvarligare symtom och reagerar sämre på behandling. Personer med dessa sjukdomar och förändringar har högre risk för suicid än personer med dessa sjukdomar men utan förändringar. Att differentiera sjukdomarna efter om sådana trauman finns eller inte finns ger därför större precision i diagnostik och behandling.

Reducerad hippocampusvolym har länge ansetts som karaktäristiskt för depression och PTSD, men bör således snarast tillskrivas förändringar som fölid av tidiga barndomstrauman. Personer med sådana förändringar har också en reducerad volym i hjärnbalken, corpus callosum, samt ökad risk för autoimmuna, metaboliska och kardiovaskulära sjukdomar.

Vid PTSD samt svår ångest och panik finns en överreaktivitet hos amygdala samt en överaktivitet i insula som har med perception av somatiska stimuli att göra. Detta är kombinerat med en underaktivitet i prefrontala kortex och i främre gyrus cinguli, som svarar för förmågan att sätta ord på upplevelserna. Kvinnor som utsatts för sexuella övergrepp i tonåren har också en minskad volym av hiärnbalken.

En god hiärnfunktion kräver ett fritt flöde av stimuli och responser mellan de två hïarnhalvorna. Hög nivå av stresshormoner hämmar myeliniseringen, vilket leder till en reducerad volym i hï̈rnbalken. Därmed hämmas strömmen av stimuli och responser. Detta kan bl.a. göra att personerna snabbt skiftar mellan logiskt rationell

\section{Hjärnan har behov av att skapa gestalter, sammanhängande bilder och tankar som gör tillvaron begriplig. Förmår inte perso- nen skapa trovärdiga problemlösningar, söker hen orsakerna på annat håll.}

och starkt känslomässig kommunikation, karaktäristiskt för borderline personlighetsstörning. Reducerad volym i hïarnbalken finns hos poikar med vanvård (negligering) i tidig barndom och hos flickor som utnyttjats sexuellt under tonåren.

Ett annat område av betydelse när det gäller självmord, dvs. att mörda sitt själv, är precuneus, som ligger mellan parietal- och occipitalloben (cuneus). I precuneus finns nervkärnor som utvecklar mentalisering, förmågan att kognitivt och emotionellt förstå sig på andra människor och därigenom också skapa bilder av sitt eget siälv.

\section{Sammanhängande förståelse}

Män. De trauman som går djupast in hos pojkar är brister i tidig barndom vad gäller fysiskt och emotionellt omhändertagande, vanvård, neglekt. Dessa män har reducerad volym i såväl hippocampus som corpus callosum. De utvecklar ett mer distant och undvikande beteende, vilket kan fördjupas till klinisk depression. Liknande hïärnförändringar finns efter såväl tortyr som mobbning (Emdad, 2011).

I tidig barndom lär människan sig att hantera sina affekter och att skapa en miuk och differentierad anknytning som modell för senare relationer. När detta inte fungerar drar de sig i stället tillbaka in i sin enslighet. Därmed skapas ett längre mentalt avstånd mellan den blivande mannen och andra människor med lägre förmåga än normalt att läsa av mimik och kroppsspråk, förstå samspelet och anpassa sig flexibelt. Vid svåra påfrestningar reagerar de inte i första hand med utåtriktad ångest utan med djupa, svåråtkomliga depressioner. Signifikanta samband mellan undvikande copingstrategier och suicidalitet finns emellertid både hos patienter som giort suicidförsök och hos deprimerade patienter utan suicidförsök, oberoende av andra sårbarhetsfaktorer (Ambrus, 2016).

Kvinnor. Kvinnorna däremot rapporterar framför allt fysisk och psykisk misshandel vid nio till tolv års ålder. Traumatisering genom sexuellt utnyttjande samt bevittnande av våld mot syskon sträcker sig längre upp i tonåren.

Dessa påfrestningar ger upphov till starka reaktioner från den hotade kroppen (via insula) och massor av känslor (via hypothalamus). Dessa aktiverar försvarsmekanismer (via amygdala). Resultatet blir en kvarstående hyperreaktivitet i amygdala och en reducerad volym av hïrnbalken med försämrad kommunikation mellan höger och vänster hïärnhalva. Dessa kvinnor har även reducerad volym av hippocampus samt de som utnyttjats sexuellt även av corpus callosum. Sammantaget ger detta en ökad benägenhet för förhöjd aktiveringsnivå, ökade ångestupplevelser och därmed ökad önskan att tidigt söka hjälp för lindring och stöd jämfört med männen.

Män och kvinnor. Den djupt liggande depressionen hos män med drag av undvikande bidrar sannolikt till deras motvilja mot att acceptera tecken på psykisk störning och livströtthet. Dessa män är rimligen svårare att diagnosticera och behandla än kvinnor med en hyperreaktiv amygdala. De senare uppfattar också lättare kroppsliga symtom förmedlade av insula samt har en oförmåga att kontrollera sin ångest, genom förändringar som ger underaktivitet i prefrontala kortex och i främre gyrus cinguli. Däremot har de i övrigt både en god språkutveckling och nära kontakt med andra människor, vilket underlättar diagnostik och behandling.

Hjärnan har behov av att skapa gestalter, sammanhängande bilder och tankar som gör tillvaron begriplig. 
Förmår inte personen skapa trovärdiga problemlösningar, söker hen orsakerna på annat håll. Valet faller ofta på brister i den egna personligheten. Självbilden, som ju byggs upp av andras omdömen och baseras på mentaliseringsförmågan (precuneus) drabbas av kritisk granskning. Besvikelsen gör att självkänslan och självförtroendet sjunker. Självet bedöms svagt, odugligt och bara till besvär. I nära interaktion med upplevd ångest bildar detta samt känslor av skuld och skam en destruktiv nedåtgående spiral. Skam är upplevelsen av andras ogillande, ett förstadium till ett smärtsamt uteslutande ur gruppgemenskapen (Eisenberger, 2003). Flickor som varit utsatta för tidiga och under lång tid upprepade sexuella övergrepp berättar att de kan känna sig osäkra på om de ens är en människa (Wetterlöv, 2015). Dissociationsfenomen är inte heller ovanliga. Likheterna med den suicidala processen är tydliga.

Barn och ungdomar möter stora svårigheter, som ibland växer till psykiska trauman. Detta skapar en delpopulation människor med en varierande mängd hiärnförändringar med nedsatta funktioner. Under goda miljöbetingelser lyckas de flesta kompensera för dessa. Kommer nya svåra påfrestningar, som de inte lyckas hantera, utvecklar de kliniska tillstånd av PTSD, ångest och depression. En del av dessa utvecklar en färdig suicidplan som reservutgång. Relativt sett få av dessa utsätts för en ytterligare ofta banal påfrestning, vilket gör att krutdurken exploderar i en suicidhandling. Mer eller mindre slumpmässigt dör några av dessa i självmord.

\section{Forskning och klinik}

Detta understryker betydelsen av Teichers huvudbudskap att barndomstrauma ofta har stor betydelse för uppkomsten av psykisk sjukdom. PTSD, ångest och depression och sannolikt även andra psykiska sjukdomar bör därför subgrupperas efter om psykiska trauman under uppväxten förekommer eller ej.

Många av dessa fynd måste emellertid reproduceras och bli än mer detalirika. Denna forskning ger också upphov till en stor mängd nya och alltmer precisa hypoteser, som behöver ytterligare beforskas. Dessa rön är också av stor klinisk betydelse. De stärker uppfattningen att ångest och depression kan ses som olika faser i samma grundläggande process. Samspelet mellan PTSD, ångest, depression och suicidalitet bör beaktas i diagnostik och behandling.

\section{REFERANSELISTE}

Ambrus L. (2016). Undvikande copingstrategier var kopplade till siälvmord. Läkartidningen, 42, 1800.

Ehnvall A., Parker G.B., Hadzi-Pavlovic D. \& Mahli G. (2008). Perception of rejecting and neglectful parents in childhood relates to lifetime suicide attempts for females - but not for males. Acta Psychiatrica Scandinavica, $117(1), 50-56$.

Eisenberger N.I., Lieberman M.D., Williams K.D. (2003). Does rejection hurt? An FMRI study of social exclusion. Science, 10, 302(5643), 290-2.

Emdad R. (2011). Mobbning kan leda till självmord. Arbetsmiliöforskning.se, 22 november 2011.

FORTE (2015). Problemet självmord. Stockholm: Forte. https://forte.se/ publikation/forskning-i-korthet-problemet-sjalvmord/

Fässberg F. \& Lundberg L. (2015). Mäns frånvaro i vården. En litteraturbaserad studie om samband mellan maskulina normer och mäns vårdsökande för psykisk ohälsa. Folkhälsovetenskapligt program med hälsoekonomi 180 hp. Examensarbete i forlkhälsovetenskap med hälsoekonomi I, Vt 2015. https://gupea.ub.gu.se/bitstream/2077/49039/1/gupea_2077_49039_1.pdf

Rutz W. (2016). «Manlig depression», stress och suicid i förändringstider. Tidskriften för Svensk psykiatri, 4, 34-36.

Rutz W. (2016). Gotlandsstudien. Tidskriften för Svensk psykiatri, 4, 37-38.

Rutz W., von Knorring L. \& Wålinder I., (1992). Long-term effects of an educational program on depressive disorders given to general practitioners given by the Swedish Committee for the prevention and treatment of depression. Acta Psykiat Scand, 1992 a, 85, 83-88.

Rutz W. (1992). Evaluation of an educational program on depressive disorders given to general practitioners on Gotland. Short- and long-term effects. Linköping: Linköping University Medical Dissertations, 1992 b.

Rutz W., Wålinder I., von Knorring L., Pihlgren H. \& Rihmer A. (1995). Depression hos män underbehandlas? Hög frekvens plötsliga, oväntade siälvmord. Läkartidn., 92, 3893-3900.

Rutz W., Wålinder I., von Knorring L., Rihmer A. \& Pihlgren H. (1997). An update of the Gotland Study. London: Martin Dunitz Ltd.

Teicher M.H. \& Samson I.A. (2013). Childhood maltreatment and psychopathology: A case for ecophenotypic variants as clinically and neurobiologically distinct subtypes. Am I Psychiatry, 170(10), 1114-33. doi: 10.1176/appi. ajp.2013.12070957.

Teicher M.H. \& Parigger A. (2015). The 'Maltreatment and Abuse Chronology of Exposure' (MACE) Scale for the Retrospective Assessment of Abuse and Neglect During Development. Public Library of Science, PLOS, 25 februar 2015. http://dx.doi.org/10.1371/journal.pone.0117423

Teicher M. H. et al. (2016). Brain structural and functional sequelae of early life adversity. Föredrag för American Psychosomatic Society, 15 oktober 2016. https://drteicher.files.wordpress.com/2016/10/child_abuse_brain_ psychosomatic_aps_2016.pdf

Van der Kolk B. (2015). The Body Keeps the Score: Brain, Mind, and Body in the Healing of Trauma. Penguin Books.

Wetterlöv I. (2015). Traumarelaterad skam. Tidskrift för Svensk Psykiatri, 4, 21. WHO. (2014) Preventing suicide - a global imperative, 2014. www.who.int

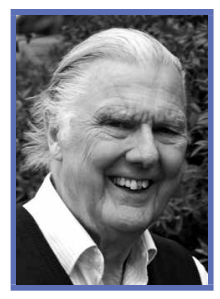

JAN BESKOW är pensionerad professor och psykiater, verksam vid Sahlhgrenska Akademin, Göteborgs universitet och Psykologiska institutionen vid Linköpings universitet, samt inom Suicidprevention i Väst, SPIV, lokaliserat till Göteborg. 